\title{
The Relationship between M-antigen and Opacity Factor in Group A Streptococci
}

\author{
By JEAN P. WIDDOWSON, W. R. MAXTED, \\ DORIS L. GRANT AND ALISON M. PINNEY \\ Cross-Infection Reference Laboratory, Central Public Health Laboratory, \\ Colindale Avenue, London, $\mathrm{NW}_{9} 5 \mathrm{HT}$
}

(Accepted for publication 23 November 1970)

SUMMARY

M-protein and the opacity factor (OF) were both extracted by Lancefield's method from certain types of group A streptococci. The two proteins could not be separated by fractional precipitation with ammonium sulphate, column chromatography or polyacrylamide gel electrophoresis. The OF appeared to be closely associated with the high molecular weight fraction of the M-antigen, and there is some evidence that the two may form part of the same molecule.

M-protein and the OF were sought in various other extracts and preparations of M-positive and M-negative variants of serotypes which gave a positive serum opacity reaction (SOR). In all preparations from M-positive variants, the two proteins were always present. In M-negative variants, the OF present in the wall-membrane fraction could be extracted only by 'phage-associated' lysin. All other extracts from M-negative variants were SOR-negative and M-negative. In the SOR-positive extract obtained by phage lysin treatment of $M$-negative variants, no $M$-antigen could be detected by precipitin tests, though the extracts contained a protein of similar electrophoretic mobility to the precipitin-positive protein in the extracts of the M-positive variants of the same serotype.

\section{INTRODUCTION}

The ability to produce opacity in horse serum is confined to certain M-types of group A streptococci (Gooder, I96r; Top \& Wannamaker, 1968a). Members of M-types 2, 4, 9, Ir, I3, 22, 25, 48 and 49 invariably give a positive serum opacity reaction (SOR), while members of most other M-types give a negative reaction. $M$ negative variants of members of SOR-positive serotypes possess an opacity factor (OF) but it can be demonstrated only in the wall-membrane fraction, or in extracts made with phage-associated lysin (Widdowson, Maxted \& Grant, 1970). In M-positive variants, however, the OF passes freely into the supernatant during growth and is readily extracted from cells by various methods including extraction with hot acid (Lancefield, I928), which is used conventionally for the extraction of M-antigen.

The OF is protein in nature (Hill \& Wannamaker, 1968) and its serological specificity corresponds to the M-type from which it was derived, in that it is inhibited by antisera prepared against members of the same $\mathrm{M}$-type but not by antisera for heterologous M-types (Widdowson et al. 1970). The correlation with T-antigen pattern 
is less clear (Top \& Wannamaker, 1968 b). In view of the apparent association between $\mathrm{OF}$ and $\mathrm{M}$-antigen, we investigated the possibility that there might be a close chemical relationship between the two proteins.

\section{METHODS}

Strains. Strains of group A streptococci were classified by T-typing (Griffith, 1934) and M-typing (Swift, Wilson \& Lancefield, I943). A stock type 49 M-positive strain (B 737/34) and matt (M-positive) and glossy (M-negative) variant strains of a stock type 2 strain (SF 59) were used in the main part of the investigation. Matt and glossy variants of other strains were used in some experiments; the isolation and characterization of these variants have already been described (Widdowson et al. 1970).

Sera. M-typing antisera were prepared by the Streptococcus Reference Laboratory, Colindale.

Medium. The growth medium was Todd-Hewitt Broth (Oxoid) to which $\mathrm{I} \%(\mathrm{w} / \mathrm{v})$ Neopeptone (Difco) had been added. Cultures were grown at $37^{\circ}$ for $24 \mathrm{~h}$. before harvesting by centrifugation.

\section{Extraction methods}

Lancefield extraction. Growth from $24 \mathrm{l}$. of broth was washed twice in normal saline and extracted twice at $100^{\circ}$ for $10 \mathrm{~min}$. with saline adjusted to $\mathrm{pH} 2$ with I N-HCl as described by Lancefield \& Perlmann (1952). The cooled extract was adjusted to $\mathrm{pH} 7.5$ with I N-NaOH.

Deoxycholate extracts. Cells harvested from $500 \mathrm{ml}$. of culture were washed with saline and the wall-membrane fraction was separated after Mickle disintegration (Michel \& Gooder, 1962). This was extracted for $16 \mathrm{~h}$. at $4^{\circ}$ as described by Top \& Wannamaker (1968b).

Extraction with alkali. A hot-alkali method similar to that of Fox \& Wittner (1969) was used, except that whole washed cells were extracted rather than cell walls.

Extraction with urea. Bacteria harvested from $250 \mathrm{ml}$. of culture were suspended in $20 \mathrm{ml}$. of $8 \mathrm{M}$-urea plus $0.4 \mathrm{M}$-mercaptoethanol, and stirred overnight at room temperature. The suspension was centrifuged and the supernatant liquid dialysed at $4^{\circ}$ against frequent changes of distilled water for $72 \mathrm{~h}$.

Extraction by phage-associated lysin. Bacteria from $400 \mathrm{ml}$. of culture were suspended in $25 \mathrm{ml}$. of $4 \mathrm{M}-\mathrm{NaCl}$ and $25 \mathrm{ml}$. phage lysin for $30 \mathrm{~min}$. at $37^{\circ}$ (Gooder \& Maxted, 1958). The mixture was centrifuged at $3500 \mathrm{~g}$ for $15 \mathrm{~min}$. and the supernatant was removed and dialysed against distilled water at $4^{\circ}$ for $24 \mathrm{~h}$.

Extracts that required concentration before activity could be detected were concentrated in dialysis bags suspended in Carbowax 6000 (Union Carbide (U.K.) Ltd, Hythe, Southampton) at $4^{\circ}$. All extracts were stored at $-20^{\circ}$ until required.

\section{Fractionation and purification procedures}

Ammonium sulphate fractionation of crude Lancefield extracts. The M-protein extracted by Lancefield's method was precipitated by bringing the $\mathrm{pH}$ of the crude extract $(220 \mathrm{ml}$.) to 2 with $6 \mathrm{~N}-\mathrm{HCl}$. This precipitate was dissolved in saline $(\mathrm{pH} 7 \cdot 5)$ and treated with ribonuclease (Lancefield \& Perlmann, 1952). Ammonium sulphate was added to $33 \%$ saturation and the precipitate $\left(\mathrm{P}_{33}\right)$ collected and dissolved in saline ( $\mathrm{pH}$ adjusted to 7.5 with I $\mathrm{N}-\mathrm{NaOH}$ ). The supernatant was brought to $60 \%$ saturation with $\left(\mathrm{NH}_{4}\right)_{2} \mathrm{SO}_{4}$ and the precipitate (P60) re-dissolved in saline $(\mathrm{pH} 7 \cdot 5)$. 
All precipitates and supernatants were dialysed against frequent changes of distilled water for $72 \mathrm{~h}$. at $4^{\circ}$. At all stages of fractionation samples of supernatants and precipitates were reserved for M-antigen and OF tests (see below).

Column chromatography on Sephadex G-Ioo and G-200. Sephadex G-100 and G-200 (Pharmacia, Uppsala, Sweden) were soaked overnight in distilled water, equilibrated with veronal buffer, $\mathrm{pH} 8 \cdot 6(\mathrm{I} \cdot 26 \mathrm{~g}$. diethylbarbituric acid $+6 \cdot 86 \mathrm{~g}$. barbitone sodium/ 1.) at $4^{\circ}$, and packed into a column $25 \mathrm{~cm} . \times 2.5 \mathrm{~cm}$. The sample (3 to $5 \mathrm{ml}$.) was added and washed in twice with its own volume of buffer before elution at a flow-rate of $20 \mathrm{ml} / \mathrm{h}$. (G-200) or 40 to $50 \mathrm{ml} . / \mathrm{h}$. (G-100).

Column chromatography on carboxymethyl cellulose (CMC). Carboxymethyl cellulose (Whatman Chromedia CMII) was soaked overnight in water and then washed with several litres of I N-NaOH. After neutralization with I $\mathrm{N}-\mathrm{HCl}$ the resin was washed in distilled water. The fines were removed by aspiration and the washed resin equilibrated with the starting buffer ( 0.03 M-sodium acetate buffer, $\mathrm{pH} 4)$ at $4^{\circ}$ and packed into a column $20 \times 1.5 \mathrm{~cm}$. The sample ( 3 to $5 \mathrm{ml}$.) was added and the column eluted with $0.1 \mathrm{M}$-acetate buffer $\mathrm{pH} 5.5$ until the $\mathrm{pH}$ of the effluent reached 5.5 . Elution was continued with $0 \cdot 1 \mathrm{M}-\mathrm{K}$ phosphate buffer $\mathrm{pH} 7$ until the effluent $\mathrm{pH}$ reached 7 (Fox \& Wittner, 1965).

Polyacrylamide gel electrophoresis. The $7.5 \%$ acrylamide gels $(5.0 \mathrm{~cm}$. long $\times$ $0.5 \mathrm{~cm}$. diameter) and buffer solutions were made as described by Davis (1964), except that the large-pore gel was omitted and the sample (200 $\mu \mathrm{g}$. protein) was applied in a $60 \% \mathrm{w} / \mathrm{v}$ sucrose solution. Electrophoresis was carried out at $\mathrm{pH} 8.9$ and I $50 \mathrm{~V}$ for $30 \mathrm{~min}$. Gels were stained with I \% Amido Black in $7 \%$ (v/v) acetic acid for I h. and destained in changes of $7 \%$ acetic acid for $36 \mathrm{~h}$.

In some experiments, slices $(0.25 \mathrm{~cm}$. thick) of unstained gels were moistened with saline and placed in the outer wells of a gel diffusion slide, the centre well of which contained absorbed anti-M serum. If a gel slice contained M-protein, a precipitin line developed. The OF could be detected by the development of opaque areas in polyacrylamide gel slices after $48 \mathrm{~h}$. incubation at $37^{\circ}$ in horse serum.

Monitoring of fractions. The protein content of fractions was determined by the method of Lowry, Rosebrough, Farr \& Randall (I95I). The extinction at $75^{\circ} \mathrm{nm}$. of the sample tubes $(0.2 \mathrm{ml}$. sample $+2 \mathrm{ml}$. reagent $\mathrm{C}+0 . \mathrm{I} \mathrm{ml}$. Folin \& Ciocalteu's reagent) was read against a blank containing $0.2 \mathrm{ml}$. of the appropriate buffer in place of the test sample. Protein contents were calculated from a standard curve $\left(E_{750} / \mu \mathrm{g}\right.$. protein $/ \mathrm{ml}$.) for bovine serum albumin. Where required, measurements of extinction at 260 and $280 \mathrm{~nm}$. were made in I cm. silica cells in a Unicam SP 500 spectrophotometer. The presence of M-antigen was detected by double gel diffusion in I \% (w/v) Ionagar against the specific anti-M serum, and against a heterologous $\mathrm{M}$-antiserum as a control.

Fractions were tested for OF by incubating $0.2 \mathrm{ml}$. with I $\mathrm{ml}$. of horse serum containing $\mathrm{I}$ in $5000(\mathrm{w} / \mathrm{v})$ merthiolate at $37^{\circ}$ for $\mathrm{I} 8 \mathrm{~h}$. After incubation, $\mathrm{I} \cdot 2 \mathrm{ml}$. of saline was added to each tube and the opacities were read at $475 \mathrm{~nm}$. in a Unicam SP600 spectrophotometer. Where necessary, fractions were pooled and concentrated in Carbowax before testing for M-antigen or OF.

Detection of $M$-antigen and $O F$ in various crude extracts and subcellular fractions. Preparations of culture supernatants and the cytoplasmic fraction (Widdowson et al. 1970) were tested for OF and, after concentration, for M-antigen as described above. 


\section{RESULTS}

Ammonium sulphate fractionation of Lancefield extracts. Table I shows the fate of the OF from an extract of a type 49 strain during the process of purification for $\mathrm{M}$-antigen. At every stage in the procedure the opacity factor was found to be inseparable from the M-protein. The final product (P60 fraction) contained both activities. Some activity (both OF and M-antigen) was also apparent in the $\mathrm{P}_{33}$ fraction. At each stage of purification the protein content was determined (Lowry et al. 195I) and the approximate 'titres' for $M$ and OF activity measured by testing twofold serial dilutions. The overall increase in specific activities in the $\mathbf{P} 60$ fraction compared with those of the crude extract was, for both factors, approximately fivefold.

\section{Table I. Purification of $M$-antigen and $O F$ from a crude Lancefield extract of a type 49 strain}

\begin{tabular}{|c|c|c|c|c|c|c|c|}
\hline Fraction & $\begin{array}{l}\text { Volume } \\
\text { (ml.) }\end{array}$ & $\begin{array}{c}\text { Protein } \\
\text { content } \\
\text { (mg./ } \\
\text { ml.) }\end{array}$ & $\overbrace{\begin{array}{c}\text { M- } \\
\text { antigen }\end{array}}^{\text {Titre }}$ & OF & 'Units'/m & s.t of & $\begin{array}{c}\text { Purifica- } \\
\text { tion } \ddagger \\
\text { factor of } \\
\text { M-antigen } \\
\text { and OF }\end{array}$ \\
\hline Crude Lancefield extract & 220 & 2.05 & $1 / 8$ & $1 / 16$ & $3 \cdot 9$ & $7 \cdot 8$ & $I \cdot O$ \\
\hline $6 \mathrm{~N}-\mathrm{HCl}(\mathrm{pH} 2)$ precipitate & 25 & $2 \cdot 5$ & $\mathbf{I} / 32$ & $\mathrm{I} / 64$ & $12 \cdot 9$ & $25 \cdot 8$ & $3 \cdot 3$ \\
\hline $\begin{array}{l}\mathrm{pH} 2 \text { supernatart (neutralized to } \\
\mathrm{pH} 7.5 \text { ) }\end{array}$ & 222 & $1 \cdot 7$ & $\mathrm{I} / 2$ & 0 & $\mathrm{r} \cdot 2$ & 0 & - \\
\hline $\begin{array}{l}\text { pH } 2 \text { precipitate after ribonuclease } \\
\text { treatment }\end{array}$ & 26 & $2 \cdot 2$ & $1 / 32$ & $\mathrm{I} / 64$ & $14 \cdot 5$ & $29 \cdot 0$ & $3 \cdot 7$ \\
\hline $33 \%\left(\mathrm{NH}_{4}\right)_{2} \mathrm{SO}_{4}$ precipitate $\left(\mathrm{P}_{33}\right)$ & 5 & $2 \cdot 2$ & I/4 & $I / 8$ & $1 \cdot 8$ & $3 \cdot 6$ & $一$ \\
\hline $60 \%\left(\mathrm{NH}_{4}\right)_{2} \mathrm{SO}_{4}$ precipitate (P6o) & 20 & $I \cdot 75$ & $1 / 32$ & $r / 64$ & I $8 \cdot 0$ & $36 \cdot 0$ & $4 \cdot 6$ \\
\hline $60 \%\left(\mathrm{NH}_{4}\right)_{2} \mathrm{SO}_{4}$ supernatant $(\mathrm{S} 60)$ & 60 & 0.1 & 0 & 0 & 0 & 0 & - \\
\hline $\begin{array}{l}60 \%\left(\mathrm{NH}_{4}\right) \mathrm{SO}_{4} \text { supernatant } \\
\text { concentrated ro-fold }\end{array}$ & 6 & $1 \cdot 0$ & 0 & 0 & 0 & 0 & - \\
\hline \multicolumn{8}{|c|}{$\begin{array}{l}\text { * Determined by testing twofold dilutions for M-antigen by gel diffusion against homologous } \\
\text { ntiserum and for OF by incubation with horse serum (see Methods). } \\
\dagger \text { 'Units'/mg. calculated by assuming that last twofold dilution to give a positive reaction (for } \\
\text { A-antigen or OF) contained I unit/ml. } \\
\ddagger \text { Purification factor for each fraction calculated relative to crude Lancefield extract. } \\
\text { - No purification. }\end{array}$} \\
\hline
\end{tabular}

When the P6o fraction dissolved in saline was carefully adjusted to $\mathrm{pH} 5 \cdot 3$ to 5.5 , a flocculent precipitate was formed which contained all of the $\mathrm{M}$-protein and all of the opacity-producing material present in the original $\mathrm{P} 60$ fraction.

CMC chromatography of P6o fractions. The P 60 fractions of the M-positive type 49 and type 2 strains were subjected to $\mathrm{CMC}$ chromatography with a stepwise $\mathrm{pH}$ gradient from 4.0 to $7 \cdot 0$ (Fox \& Wittner, 1965). The resultant chromatogram (Fig. I) for type 49 shows that the protein was separated into two distinct peaks. The first peak emerged as the $\mathrm{pH}$ of the buffer approached 5.5 , and the second as the $\mathrm{pH}$ changed from 5.5 to 7. This was in agreement with the results of Fox \& Wittner (1965, 1969) for other M-antigens. The first peak contained M-protein but the $E_{260 / 280}$ ratio for this peak was $\mathrm{I} \cdot 7$ indicating possible contamination with residual nucleic acids. The second peak had an $E_{260 / 280}$ ratio close to I'0, indicating greater purity. The OF, like M-antigen, was detectable in both peaks. The fractions that showed maximum protein content showed both maximum precipitin and maximum SOR activity. 
The $\mathrm{P} 60$ fraction of an M-positive type 2 strain also gave two protein peaks. However, the material in the first peak gave no reaction with the specific antiserum and also had a negative SOR. All the M-protein and OF appeared to be concentrated in the second peak.

G-IOO chromatography of crude Lancefield extracts of M-positive and M-negative variants of SF 59 (type 2). Lancefield extracts of M-negative variants of SOR-positive strains apparently contain neither the opacity factor nor M-antigen. Extracts of M-positive variants of these strains contain both proteins (Widdowson et al. 1970)

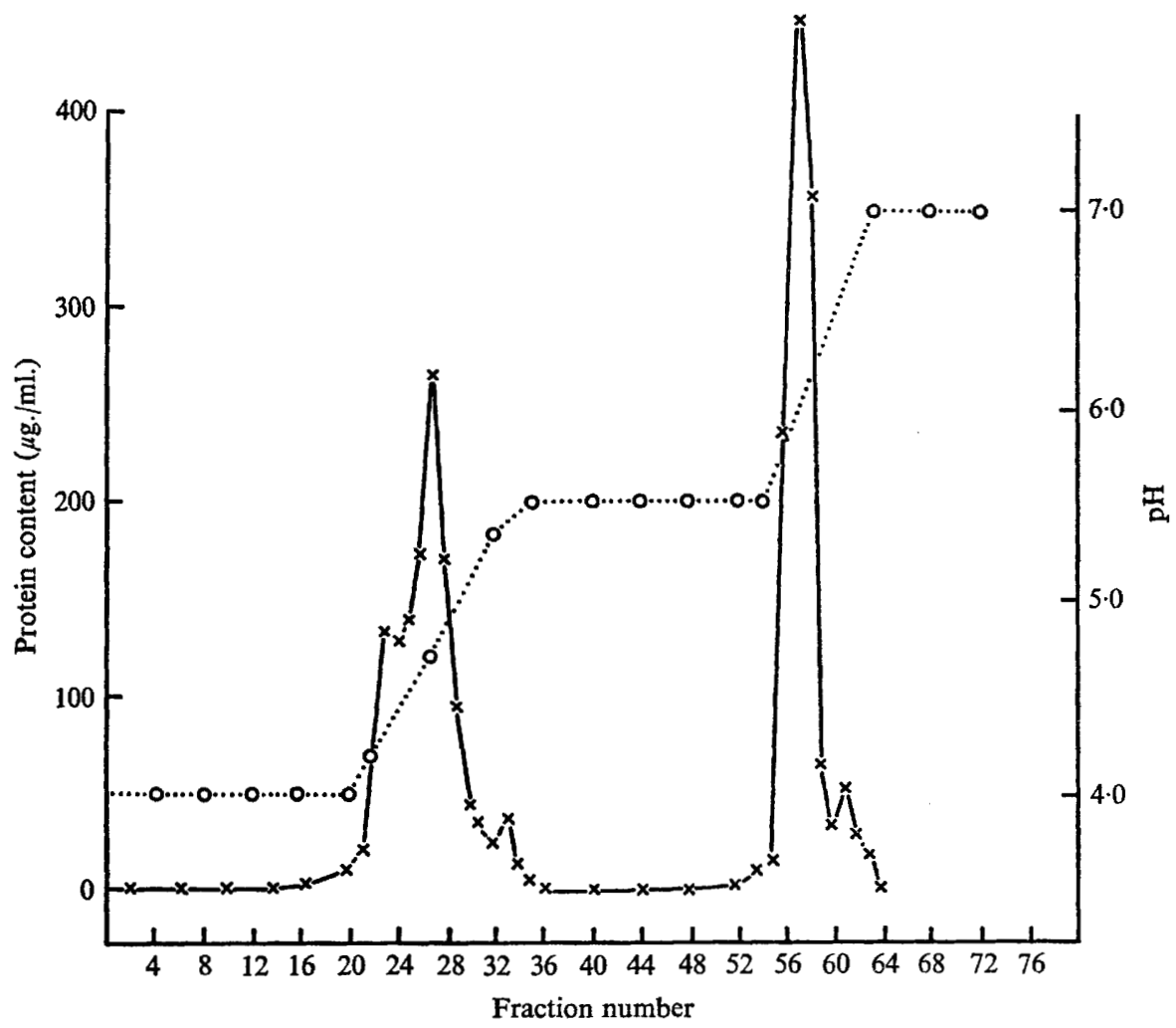

Fig. I. Chromatography of the P6o fraction of a type 49 M-protein on carboxymethyl cellulose. Fraction volume, $3 \mathrm{ml}$. Protein content, $-x-x-$; $\mathrm{pH}$ of eluate, $\cdots 0 \cdots 0 \cdots$.

Crude Lancefield extracts of M-positive and M-negative variants of strain SF 59 (type 2) were compared by column chromatography on G-Ioo Sephadex. The two extracts gave almost identical patterns from fraction I I onwards, but the extract of the $\mathrm{M}$ positive variant showed a large peak of high molecular weight material that was completely absent from the extract of the M-negative variant (Fig. 2). This peak emerged at the void volume (indicating a molecular weight of 80,000 or greater) and contained both the M-precipitin and the SOR activity of the extract. Paired variants of a type 4 strain and a type 22 strain were found to behave in a similar manner.

The high molecular weight material from G-I00 chromatography of the crude Lancefield extract of the type $2 \mathrm{M}$-positive variant was subjected to CMC chromatography as described for $\mathrm{P} 60$ fractions. The results obtained were identical with those 
given by the $\mathrm{P} 60$ fraction of this strain. The peak that emerged near to $\mathrm{pH} 7$ contained both the opacity factor and the M-precipitin activity.

$G-200$ chromatography of $P 60$ fraction of type 49 . A P 60 fraction of the M-positive type 49 strain was applied to a column of Sephadex G-200(Fig. 3). Double gel-diffusion tests showed the presence of type-specific M-antigen in all fractions from 10 to 26 . Fractions were pooled as indicated in Fig. 3 to give fractions A, B and C. Although all three were capable of precipitating with the specific antiserum, and the identity of the antigen in the separate fractions was apparent from the joining of adjacent precipitin

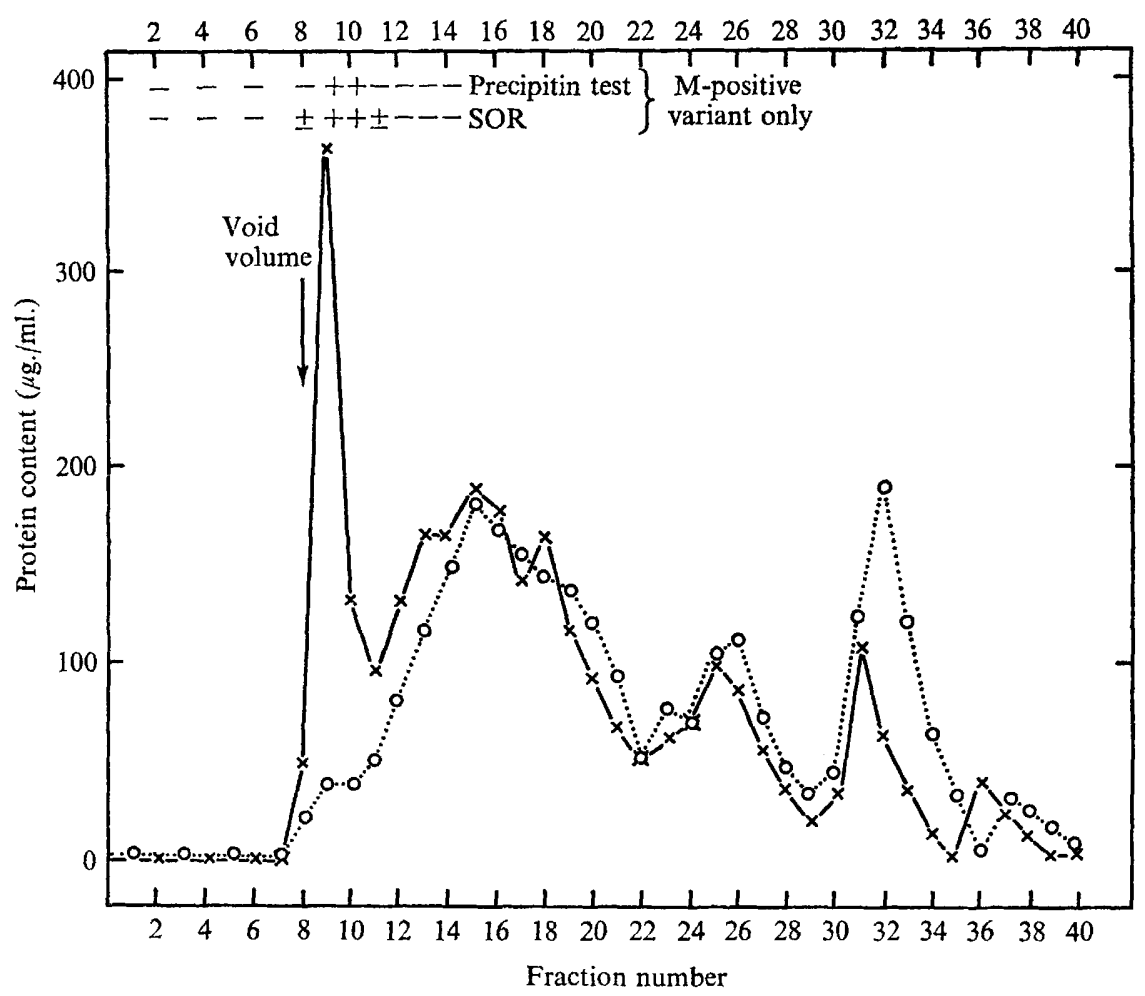

Fig. 2. Sephadex G-100 chromatograms of the crude Lancefield extract of M-positive $(-x-x \rightarrow)$ and M-negative $(\cdots 0 \cdots, \cdots)$ variants of a type 2 strain. Fraction volume, $5 \mathrm{ml}$. Fractions were tested for $M$-antigen and opacity factor: + , presence; -, absence; \pm , trace, of M-antigen or OF.

lines, only fraction $A$, which represented the high molecular weight material from the column, gave a positive SOR.

Polyacrylamide gel electrophoresis. A P 60 fraction and the G-200 fractions A, B and C of type 49 were subjected to polyacrylamide gel electrophoresis (Fig. 4). Fraction A had a darkly staining band of low mobility which was also present, though less darkly stained, in the original P 60 fraction. The faster moving bands of the P60 fraction also appeared in fraction $\mathrm{C}$ but were virtually absent from $\mathrm{A}$. However, $\mathrm{C}$ had no upper darkly staining band and the stained material began and ended lower down the gel than with fraction A. Stained polyacrylamide gels of fraction B were fainter but more or less identical with those of fraction $\mathrm{C}$. 
Slices $(0 \cdot 25 \mathrm{~cm}$.) of unstained acrylamide gel from the $\mathrm{P} 60$ fraction showed positive $M$-precipitin reactions for all protein bands by double gel diffusion (slices I to I2). However, only those corresponding to the top band (slices 2 to 6 ) showed any evidence of the opacity factor when incubated in horse serum. Faster moving bands were SORnegative. When the G-200 fractions were compared in this way, fraction A showed precipitin lines only in slices from the top $2 \mathrm{~cm}$. (slices 2 to 8 ) of the gel. In fractions $B$ and $C$ (in which the top band was absent) the precipitin lines began lower down at

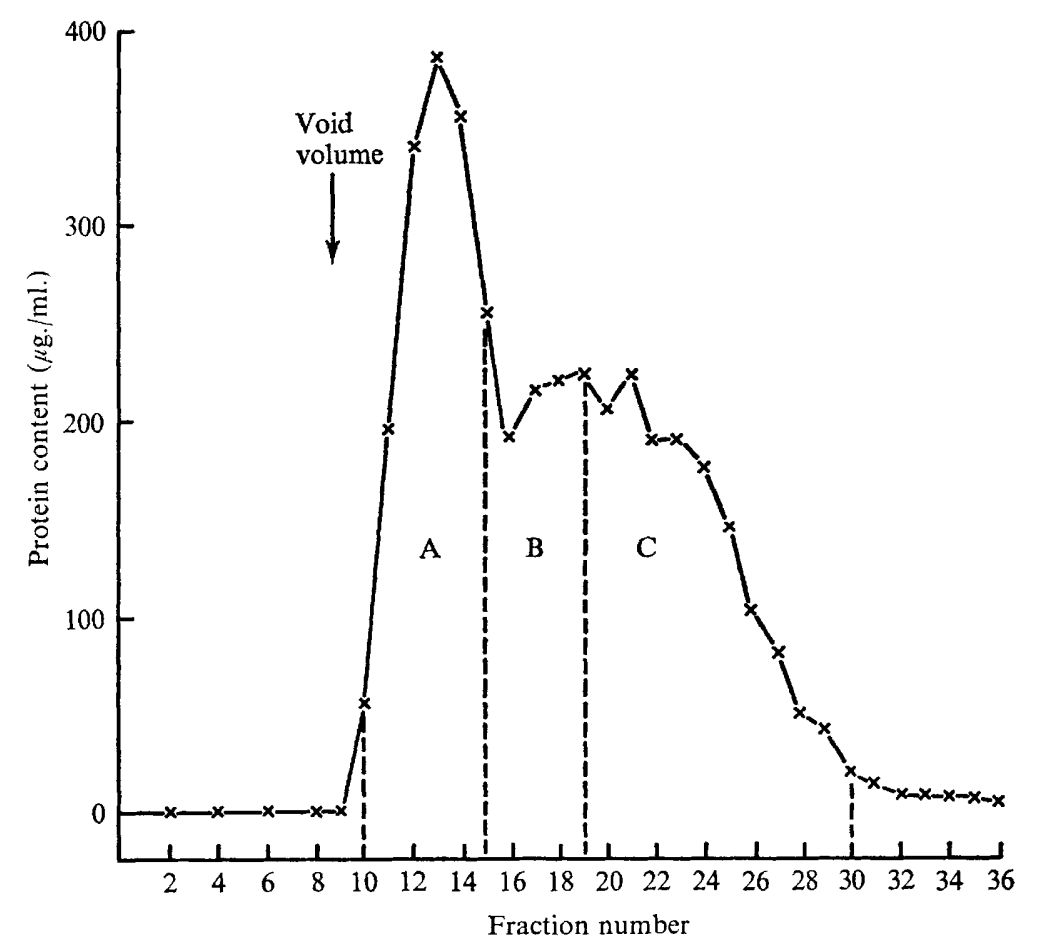

Fig. 3. Sephadex G-200 chromatogram of the P6o fraction of type 49 M-protein. Fraction size, $5 \mathrm{ml}$. Fractions pooled as denoted by A, B and C: A was M-positive and SOR-positive; $\mathrm{B}$ and $\mathrm{C}$ were $\mathrm{M}$-positive but SOR-negative.

slice 4 or 5 and extended to slice 12 ; fraction A showed SOR-positive material in slices 2 to 6 . All the bands in fractions B and C were SOR-negative. These findings are summarized in Table 2.

Detection of $M$-antigen and the opacity factor in various extracts and subcellular fractions of $M$-positive and $M$-negative variants. The $\mathrm{OF}$ and $\mathrm{M}$-antigen were both extracted by Lancefield's method from M-positive strains and had proved difficult to separate by the various methods described above. Previous work (Widdowson et al. 1970) has shown that the OF is detectable in the growth supernatant and various extracts of M-positive but not of M-negative variants. However, treatment of either variant with phage-associated lysin released SOR-positive material from the cell walls. We therefore tested growth supernatants, cytoplasm, deoxycholate extracts and ureamercaptoethanol extracts of both M-positive and M-negative variants of several different serotypes for the presence of M-antigen. In each case the SOR-positive 
materials from M-positive variants were M-positive, as shown by a line of identity with a purified P6o fraction (Fig. 5). Preparations from M-negative variants were SOR-negative and M-negative.

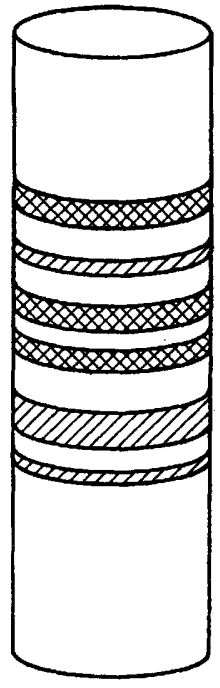

(a)

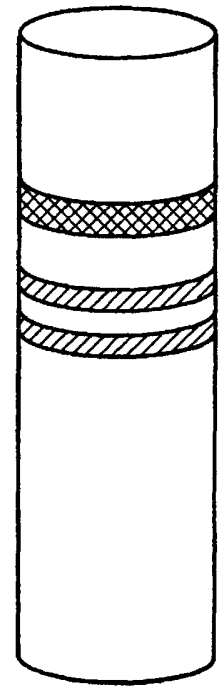

(b)

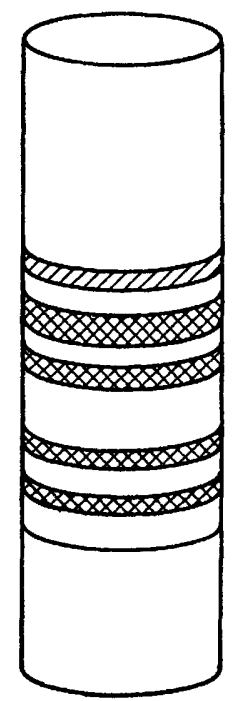

(c)

Fig. 4. Stained gels from the polyacrylamide gel electrophoresis of: (a) P60 fraction of type 49 M-protein; (b) G-200 fraction A from P6o of type 49 M-protein; (c) G-200 fraction C from P60 of type $49 \mathrm{M}$-protein. $=$ Intensely stained band; $\square=$ less intensely stained band; $-=$ faint, narrow band.

Table 2. SOR and M-precipitin activities of polyacrylamide gel slices after electrophoresis of type 49 M-protein preparation

Type 49 M-protein preparation

\begin{tabular}{|c|c|c|c|c|c|c|c|c|}
\hline \multirow{2}{*}{$\begin{array}{l}\text { Gel slice } \\
\text { no. (from } \\
\text { the top) }\end{array}$} & \multicolumn{2}{|c|}{$\begin{array}{l}\text { Unfractionated } \\
\text { P6o }\end{array}$} & \multicolumn{2}{|c|}{$\begin{array}{c}\text { Sephadex G-200 } \\
\text { pooled A }\end{array}$} & \multicolumn{2}{|c|}{$\begin{array}{c}\text { Sephadex G-200 } \\
\text { pooled B }\end{array}$} & \multicolumn{2}{|c|}{$\begin{array}{c}\text { Sephadex G-200 } \\
\text { pooled C }\end{array}$} \\
\hline & Precipitin* & SOR† & Precipitin & SOR & Precipitin & SOR & Precipitin & SOR \\
\hline I & \pm & - & - & - & - & - & - & - \\
\hline 2 & + & \pm & \pm & \pm & - & - & - & - \\
\hline 3 & + & + & + & + & - & - & - & - \\
\hline 4 & + & + & + & + & - & - & \pm & - \\
\hline 5 & + & + & + & + & + & - & + & - \\
\hline 6 & + & \pm & + & \pm & + & - & + & - \\
\hline 7 & + & - & + & - & + & - & + & - \\
\hline 8 & + & - & \pm & - & + & - & + & -- \\
\hline 9 & + & - & - & - & + & - & + & - \\
\hline Io & + & - & - & - & + & - & + & - \\
\hline I I & + & - & - & - & + & - & + & - \\
\hline 12 & + & - & - & - & + & - & + & _- \\
\hline
\end{tabular}

* In the gel diffusion test,$+=$ presence of precipitin line, $-=$ no visible line, $\pm=$ faint line.

$\dagger$ In the SOR test when gel slice incubated in horse serum, $+=$ ring of opacity, $-=$ no opacity, $\pm=$ faint opacity. 
Extracts with phage-associated lysin of both M-positive and M-negative variants of SOR- positive serotypes contain the opacity factor, and since all other preparations which contained the $\mathrm{OF}$ had proved to contain precipitating $\mathrm{M}$-antigen, we attempted to detect $\mathrm{M}$-antigen in crude phage-associated lysin extracts of M-positive and Mnegative variants of members of various serotypes. Crude phage-associated lysin extracts were concentrated in Carbowax and tested in double gel diffusion tests against the appropriate absorbed antisera. Lines of identity with purified M-antigen were seen in the extracts of $M$-positive but not of M-negative variants.

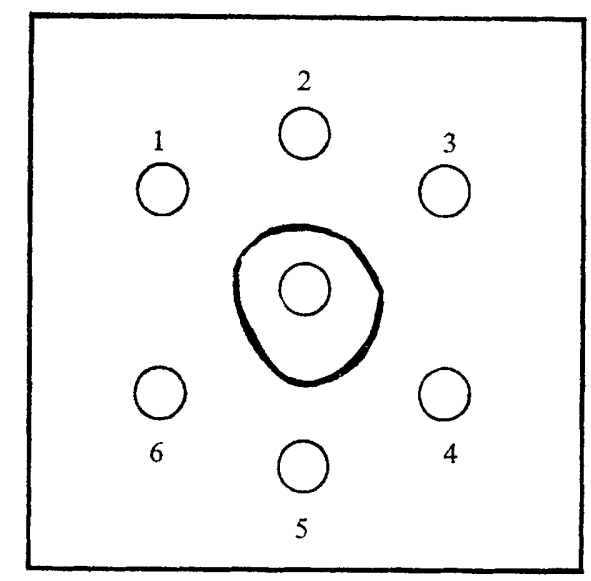

Fig. 5. Double gel diffusion slide showing the presence of $M$-antigen in various fractions and extracts of a type $49 \mathrm{M}+$ strain. Centre well contains absorbed type 49 anti-M serum. Outer wells contain: I, growth supernatant concentrated $\times 10 ; 2, \mathrm{P} 60$ fraction from Lancefield extract; 3, I \% (w/v) sodium deoxycholate extract of wall-membrane fraction, concentrated $\times 10 ; 4$, alkaline extract of whole cells; 5 , urea-mercaptoethanol extract concentrated $\times 10 ; 6$, crude Lancefield extract.

Ammonium sulphate was added at $60 \%$ saturation to the phage lysin extracts of the M-positive and M-negative variants of a type 49 strain. The $\mathrm{P} 60$ fraction was dissolved in saline at $\mathrm{pH} 7.5$ and the $\mathrm{pH}$ carefully adjusted to 5.5 by the addition of $0.2 \mathrm{~N}-\mathrm{HCl}$. In all cases the flocculent precipitate which was obtained was separated and redissolved in saline at $\mathrm{pH} 7 \cdot 5$. All the fractions were dialysed against distilled water for $72 \mathrm{~h}$. at $4^{\circ}$. All of the SOR activity in both variants appeared in the fraction precipitated at $\mathrm{pH} 5.5$ ( $\left.\mathrm{P}_{5} .5\right)$.

The fractions were also tested for precipitating M-antigen and this was found in the $\mathrm{P} 60$ fractions and the $\mathrm{P} 5.5$ fraction of the M-positive variant only. Similar results were obtained with the M-positive and M-negative variants of another SOR-positive type (type I I). Purified fractions from M-positive and M-negative variants of SORnegative serotypes (types 12 and 6) also had detectable M-antigen in the P6o and P 5.5 fractions of the M-positive variant only.

The $\mathrm{P}_{5} 5$ fractions of M-positive and M-negative variants of a type I I strain were subjected to polyacrylamide gel electrophoresis (see Fig. 6). The $\mathrm{P}_{5} \cdot 5$ fraction obtained from the phage lysin alone contained very little protein, and this appeared as a faint band about two-thirds of the way down the gel. All the other bands in the P 5.5 fractions obtained from the phage lysin extracts of the group A strains should therefore 
have been derived from the group A cell wall. Similar results were obtained with other serotypes. It is clear from the polyacrylamide gel patterns that the P 5.5 fractions of $\mathrm{M}$-positive and M-negative variants differ very little. M-precipitin activity could be detected by double gel diffusion in the top band of the P 5.5 of the M-positive variants. Although a similar band was always present in the P 5.5 of glossy variants, no precipitin activity could be detected in this band.

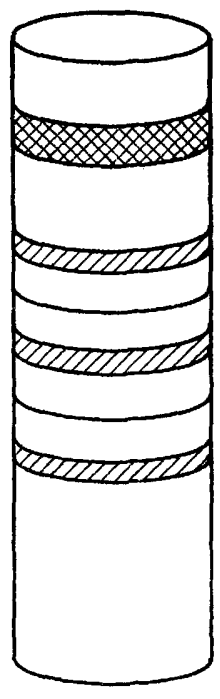

(a)

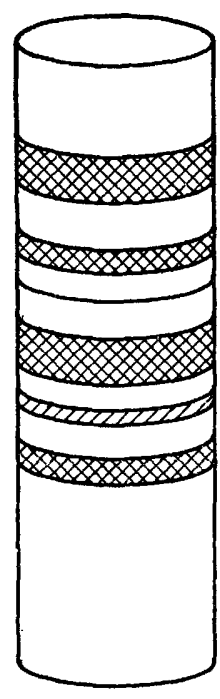

(b)

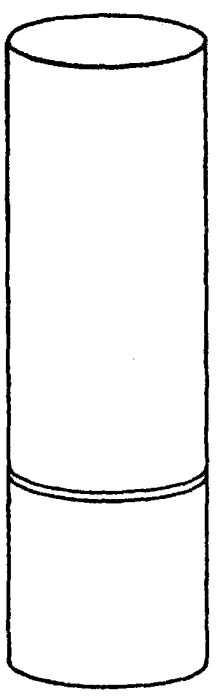

(c)

Fig. 6. Stained gels from the polyacrylamide gel electrophoresis of $\mathrm{P}_{5} .5$ fractions from: (a) the phage-associated lysin extract of a type II $\mathrm{M}+$ ve variant; $(b)$ the phage-associated lysin extract of a type II $M$-ve variant; $(c)$ phage-associated lysin (control). $=$ Intensely stained band; $\square=$ less intensely stained band; $==$ faint band; $-=$ faint narrow band.

\section{DISCUSSION}

We have obtained further evidence of a close association of $\mathrm{M}$-antigen and $\mathrm{OF}$ in M-positive variants of group A streptococci that belong to SOR-positive serotypes. Not only do the two proteins have a corresponding type-specificity, but the M-antigen can be demonstrated in all extracts of M-positive variants in which the OF is present, and the treatment of acid extracts by methods traditionally used for the purification of M-antigen, such as ammonium sulphate fractionation (Lancefield \& Perlmann, 1952) and CMC chromatography (Fox \& Wittner, I965) fail to separate the two antigens. The results of chromatography on Sephadex G-200 and the polyacrylamide gel electrophoresis with a purified P60 fraction of a type 49 strain indicate that there is indeed a very close chemical relationship between $M$-antigen and the opacity factor, but that the ability to produce SOR is associated only with the large molecular weight fraction of acid-extracted M-antigen. Fox \& Wittner (1969) suggested that the M-protein extracted by hot acid (molecular weight 20,000 to 30,000 ) is a fragmented product of a larger protein present on the cell wall. They obtained a serologically more active 
antigen (molecular weight 100,000, or greater) by extraction with alkaline buffer at $37^{\circ}$. Our results with type 49 differ from those of Fox \& Wittner with type I2, in that the P6o fractions of our acid extracts contained a large proportion of high molecular weight material as well as some smaller but still serologically active fragments. In our experience there are also considerable differences between the G-I00 chromatograms of crude acid extracts of different serotypes. SOR-positive serotypes usually have chromatograms similar to that shown in Fig. 2, with a sharp peak of serologically active, SOR-positive material emerging at the void volume. On the other hand extracts of certain other M-types, notably type 12 , have no peak at the void volume and the fractions showing precipitation with absorbed anti-M serum cover a much wider range of smaller molecular weights.

Our results do not entirely exclude the possibility that the factor responsible for the production of serum opacity may be a minor contaminant of our purified M-protein preparations, but it seems much more likely that the two activities reside in the same protein molecule. If this is so, however, SOR activity appears to be lost when the $\mathrm{M}$-antigen is fragmented by hot acid. Furthermore, the antigenic determinants for the two activities appear to be different. Antisera can be prepared that neutralize the serum opacity reaction but have little or no M-type precipitin activity, and many good anti-M sera have no anti-SOR activity. This is similar to the situation in which certain sera prepared against purified $\mathrm{M}$-antigens show good mouse protection but no bactericidal action (Brighton, 1966).

Despite our inability to separate the OF from the M-antigen in the laboratory, M-negative variants of SOR-positive streptococci possess an OF antigenically identical to the $\mathrm{OF}$ of the corresponding M-positive variant, though it can be released from the cell only by treatment with phage lysin. Although we were unable to detect any M-antigen in the phage-lysin extracts of these M-negative variants by the precipitin reaction, the electrophoretic patterns of the partially purified extracts appear to be identical with those of the corresponding extracts of the M-positive variants. This suggests that the $\mathrm{M}$-negative variants may possess at least part of the M-protein molecule.

\section{REFERENCES}

Brighton, W. D. (1966). Methods for the determination of immunity against group A Streptococcus. In Current Research on Group A Streptococcus, pp. 23I-239. Proceedings of a Symposium, Paris, July 1966. Excerpta Medica Foundation 1968.

Davis, B. J. (1964). Disc electrophoresis. II. Method and application to human serum proteins. Annals of the New York Academy of Sciences 12r, 404-427.

Fox, E. N. \& WiTTNeR, M. K. (1965). The multiple molecular structure of the M proteins of group A streptococci. Proceedings of the National Academy of Sciences of the United States of America 54, III8-II25.

Fox, E. N. \& WitTner, M. K. (I969). New observations on the structure and antigenicity of the $\mathrm{M}$ proteins of the group A streptococcus. Immunochemistry 6, I I-24.

Gooder, H. (1961). Association of a serum opacity reaction with serological type in Streptococcus pyogenes. Journal of General Microbiology 25, 347-352.

Gooder, H. \& MAXTED, W. R. (I958). Protoplasts of group A $\beta$-haemolytic streptococci. Nature, London 182, 808-809.

GrIfFITH, F. (1934). The serological classification of Streptococcus pyogenes. Journal of Hygiene, Cambridge 34, 542-584.

Hill, M. J. \& WANNAMAKER, L. W. (I968). The serum opacity reaction of Streptococcus pyogenes: general properties of the streptococcal factor and of the reaction in aged serum. Journal of Hygiene, Cambridge 66, 37-47.

6

M I C 65 
LANCEFIELD, R. C. (1928). The antigenic complex of Streptococcus haemolyticus. I. Demonstration of a type-specific substance in extracts of Streptococcus haemolyticus. Journal of Experimental Medicine 47, 91-103.

Lancefield, R. C. \& Perlmann, G. E. (1952). Preparation and properties of type-specific M antigen isolated from a group A, type I, hemolytic Streptococcus. Journal of Experimental Medicine 96, 7I-82.

Lowry, O. H., Rosebrough, N. J., Farr, A. L. \& Randall, R. J. (1951). Protein measurement with the Folin phenol reagent. Journal of Biological Chemistry 193, 265-275.

MicheL, M. F. \& GoOder, H. (I962). Amino acids, amino sugars and sugars present in the cell walls of some strains of Streptococcus pyogenes. Journal of General Microbiology 29, 199-205.

SwifT, H. F., Wirson, A. T. \& LANCEField, R. C. (1943). Typing group A hemolytic streptococci by $M$ precipitin rections in capillary pipettes. Journal of Experimental Medicine 78, $127-133$.

ToP, F. H. JUN. \& WANNAMAKER, L. W. (1968a). The serum opacity reaction of Streptococcus pyogenes. Frequency of production of streptococcal lipoproteinase by strains of different serological types and relationship to M-protein production. Journal of Hygiene, Cambridge 66, 49-58.

Top, F. H. Jun. \& WANNAMAKeR, L. W. (1968 $b$ ). The serum opacity reaction of Streptococcus pyogenes. The demonstration of multiple strain specific lipoproteinase antigens. Journal of Experimental Medicine I27, 1013-1034.

WidDowson, J. P., MAXTED, W. R. \& GRANT, D. L. (1970). The production of opacity in serum by group A streptococci and its relationship with the presence of $M$ antigen. Journal of General Microbiology 6r, 343-353. 